\title{
Value of sonographic pseudogestational sac sign in the diagnosis of Meckel diverticulum in children presenting with bleeding per rectum: a 15-year prospective study
}

\author{
Samar M. El-Maadawy ${ }^{1,2^{*}} \mathbb{0}$, Nesreen Alaaeldin ${ }^{2}$ and Vassil N. Zefov ${ }^{3}$
}

\begin{abstract}
Background: Meckel diverticulum is the most common congenital abnormality of the gastrointestinal tract. Gastrointestinal bleeding is the most common complication of Meckel diverticulum in the paediatric population; the bleeding mostly occurs in the first 2 years of life. Because the diverticulum is seldom seen in clinical practice, misdiagnosis and delayed diagnosis are not uncommon. CT and nuclear studies are the most used diagnostic tools in clinical practice. However, radiation and sensitivity concerns remain an issue. Ultrasound has been suggested as an alternative diagnostic tool in diagnosing Meckel diverticulum with mixed results. The aim of our study is to assess the value of using a new sonographic sign, the pseudogestational sac sign in diagnosing Meckel diverticulum in children presenting with bleeding per rectum. Ultrasound was performed for all children. Results were correlated with nuclear studies, histopathology and clinical follow-up findings.

Results: Seventy-three children were included in our study. The pseudogestational sac sign was present in 46 (63\%) and absent in 27 (37\%) cases. Forty-five children were ultimately diagnosed as Meckel diverticulum. The age ranged from 2 months to 9 years with a mean of 2.3 years. The boy-to-girl ratio was $4.6: 1$ with $60 \%$ of children presenting during their first 2 years of life. The ultrasound performance using the pseudogestational sac sign revealed a sensitivity of $91.1 \%$, specificity of $82.1 \%$, positive predictive value of $89.1 \%$, negative predictive value of $85.2 \%$, positive likelihood ratio of 5.1, negative likelihood ratio of 0.11 and accuracy of $87.7 \%$.
\end{abstract}

Conclusion: The sonographic pseudogestational sac sign is a reliable diagnostic tool for diagnosing Meckel diverticulum in children presenting with bleeding per rectum. The sonographic diagnosis of Meckel diverticulum complies with the international standards of "Image Gently".

Keywords: Meckel diverticulum, Ultrasound, Gastrointestinal haemorrhage

\section{Background}

Meckel diverticulum is a congenital intestinal deformity attributable to incomplete embryonic degeneration of the yolk tube. It takes place in approximately $2 \%$ of the population. Since Meckel diverticulum has all three layers of

\footnotetext{
*Correspondence: samarmaadawy@gmail.com

${ }^{1}$ Department of Radiology, National Cancer Institute, Cairo University,

Cairo, Egypt

Full list of author information is available at the end of the article
}

the gastrointestinal wall, it is considered a true diverticulum with gastric mucosa being the most common heterotopic tissue [1].

Despite the fact that Meckel diverticulum is the most common congenital gastrointestinal abnormality, the condition is rarely seen in clinical practice; delayed diagnosis or misdiagnosis is not uncommon adding burdens on children and their parents [2-4].

Bleeding per rectum is the most prevalent complication of Meckel diverticulum occurring mostly in the first 
2 years of life [5]. The bleeding manifests as dark red stools or considerable amount of bright red stool which can lead to life-threatening haemorrhagic shock and necessitates immediate medical attention $[3,4]$. The second most common complication is intestinal obstruction; however, adult population are more prone to experience such complication [6].

Symptomatic Meckel diverticulum can be diagnosed using a variety of imaging modalities, including conventional radiographs, ultrasound, nuclear studies and CT [7-9]. Computed tomography has been reported to be the imaging modality of choice in diagnosing complicated Meckel diverticulum with low sensitivity and at the cost of radiation exposure [1]. In children with severe rectal bleeding, $99 \mathrm{mTc}$ pertechnetate scintigraphy has high positive and negative predictive values for detecting inflamed Meckel diverticulum. However, the sensitivity can be affected by the amount of heterotopic gastric tissue, degree of rectal bleeding and haemoglobin levels, as well as inflammatory and oedematous changes within the diverticulum $[5,10-12]$.

Ultrasound has been used to investigate Meckel diverticulum yielding mixed results with a sensitivity ranging from 0 to $93.6 \%[1,12]$. Other reports used either small sample size, case reports or retrospective study design $[6,9,13-16]$.

The aim of our prospective study is to assess the value of using a new sonographic sign, the pseudogestational sac sign in diagnosing Meckel diverticulum in children presenting with bleeding per rectum with histopathological and clinical follow-up correlation. The pseudogestational sac sign was named due to resemblance of bleeding Meckel diverticulum to early intrauterine or extrauterine gestational sac which appears as blindended cystic mass with thick echogenic wall and clear or turbid content (Fig. 1) [17].

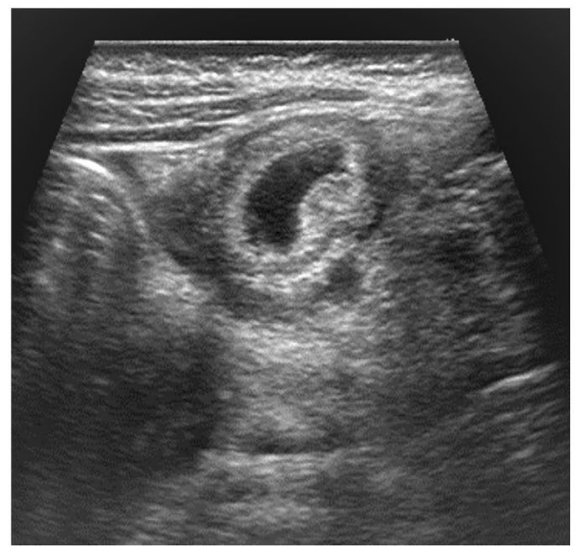

a

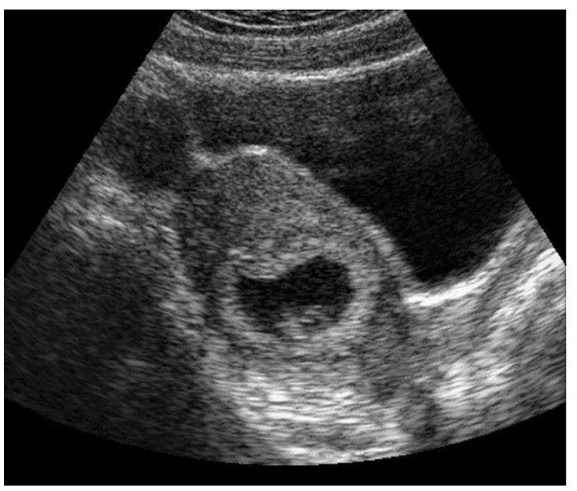

C

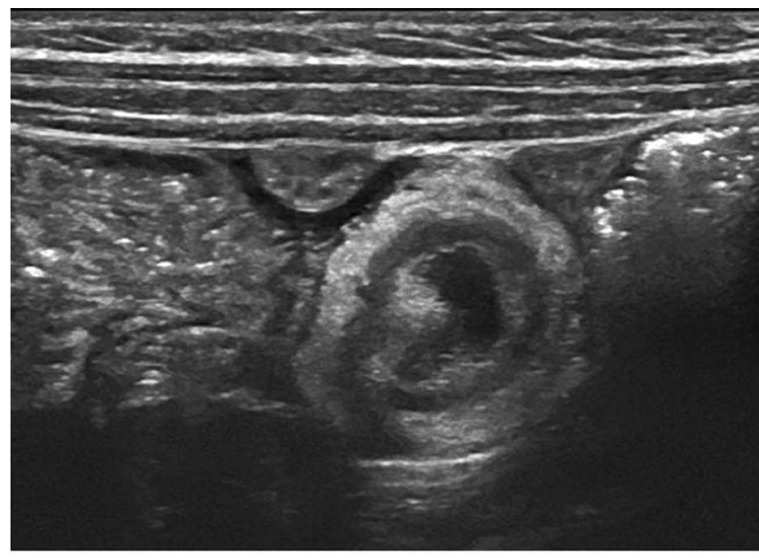

b

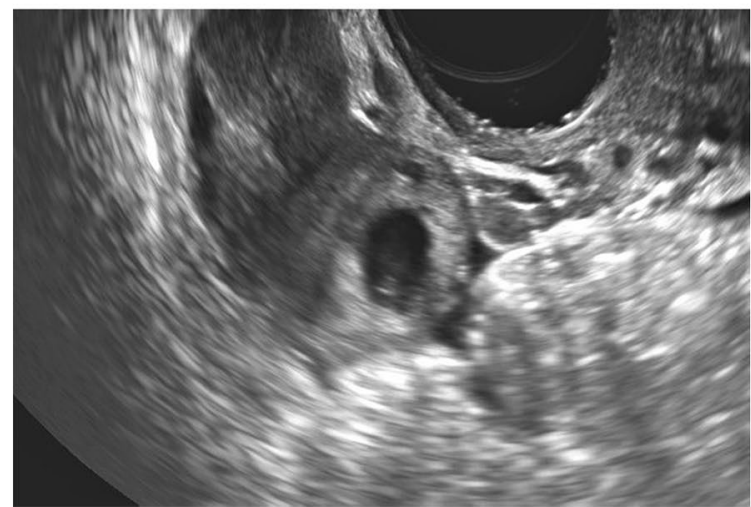

d

Fig. 1 Pseudogestational sac sign. a, b 18-month-and 20-month-old boys with bleeding per rectum showing blind-ended cystic masses with thick echogenic walls and clear or turbid content resembling an early intrauterine or extrauterine gestational sac. c, d 25-year- and 32-year-old women with early intrauterine and extrauterine (ectopic) gestational sacs 


\section{Methods}

Our prospective single-institution study included all consecutive children under the age of 18 years who were referred to the Radiology Department with clinical suspicion of Meckel diverticulum due to bleeding per rectum from January 2005 to October 2020. The study was approved by the institutional ethics committee. Written informed consent was obtained from the parents of all patients who agreed to take part in the study. The study was reported in compliance with the Standards for Reporting for Diagnostic Accuracy studies (STARD guidelines).

Inclusion criteria included all children with suspected Meckel diverticulum who are willing to perform ultrasound followed by laparoscopy if required. Exclusion criteria included patients with intussusception, patients with imaging features of partial or complete intestinal obstruction, loss of follow-up and lack of informed consent.

All children were initially assessed by x-ray abdomen in supine view as part of our institution protocol for management of children with acute abdomen.

Two senior radiologists who are highly experienced in the field of paediatric imaging performed the ultrasound examinations using (GE Healthcare Logic E9) ultrasound system with high-resolution 9L-D 2-9 MHz broad-spectrum linear probe and $\mathrm{ML}$ 6-15 $\mathrm{MHz}$ broad-spectrum linear matrix array probe with colour Doppler imaging. In case of unsatisfactory imaging due to thick anterior abdominal wall and older children, C2-9-D 2-9 MHz broad-spectrum convex probe was used.

The children were examined in supine or lateral decubitus views using a warm coupling gel to ensure child comfort and cooperation. No bowel preparation was needed. The diagnosis of Meckel diverticulum was established upon the identification of pseudogestational sac sign within the abdomen which resembles early intrauterine or extrauterine gestational sac appearing as blindended cystic mass with thick echogenic wall and clear or turbid contents. The diverticulum is usually hypervascular on colour Doppler and surrounded by inflammatory changes. The longest axial dimensions of the lesion were recorded.

Following ultrasound, 30 patients performed $99 \mathrm{~m}$ TcO4 Meckel diverticulum nuclear study after intravenous administration of $2-3 \mathrm{mCi}$ of $\mathrm{Tc} 04$ with dynamic imaging of the abdomen anteriorly and posteriorly for $1 \mathrm{~h}$ followed by static images before and after voiding the urine. Seven patients performed SPECT CT after intravenous administration $74 \mathrm{MBq}$ of $\mathrm{Tc} 04$ with dynamic images of the abdomen anteriorly and posteriorly for $1 \mathrm{~h}$ followed by static and SPECT CT images. A maximum gap of 1 week separated the ultrasound and nuclear studies.

Confirmed cases of Meckel diverticulum were treated with open or laparoscopic-assisted Meckel diverticulectomy and end-to-end ileal anastomosis. Surgical specimens were sent to the same histopathology laboratory. The pathology report included the size of the diverticulum, wall thickness, presence or absence of heterotopic gastric or pancreatic tissue and presence of complications such as perforations and surrounding inflammatory changes. Conservatively treated children were followed clinically in the outpatient clinic and by ultrasound for a period of 6 months. During follow-up, the resolution of bleeding per rectum or diagnosis of other diseases was considered negative for Meckel diverticulum.

The ultrasound findings were correlated with nuclear studies, operative and histopathology results and in cases with conservative management with clinical and imaging follow-up findings. All the data were collected by the hospital electronic medical records. The sensitivity, specificity, positive and negative predictive values, positive and negative likelihood ratios as well as accuracy of pseudogestational sac sign were calculated using Medcalc Statistical software, version 19.1 (Medcalc Software, Ostend, Belgium).

\section{Results}

Flowchart of the children in our study is shown in Fig. 2 according to STARD recommendation. Ninety-five patients were initially enrolled in our study. Twenty-two children were excluded due to the presence of intussusception, partial/complete intestinal obstruction and loss of follow-up. Following the exclusion criteria, 73 patients were ultimately included.

The ratio of boys to girls in our series was 3.9:1 with 58 boys and 15 girls. The age ranged from 4 weeks to 12 years with a median of 2.2 years.

The pseudogestational sac sign was identified in 46 cases (63.0\%). Forty-three patients were eligible for surgery all of which proved to be Meckel diverticulum by surgery and histopathology except for two cases. One patient was a 6-year-old male with negative laparoscopy finding and subsequent sigmoidoscopy and rectal polypectomy. The second case was a 1-monthold baby girl with suspected Meckel diverticulum within an umbilical hernia who proved by laparoscopy to have isolated umbilical hernia associated with omphalo-mesenteric band. Nuclear study was done for 23 patients and SPECT CT for three patients with a maximum of 1 week interval from the ultrasound all of which turned to be positive except for five patients. Three patients were treated conservatively and followed clinically and ultrasound with improvement in clinical 


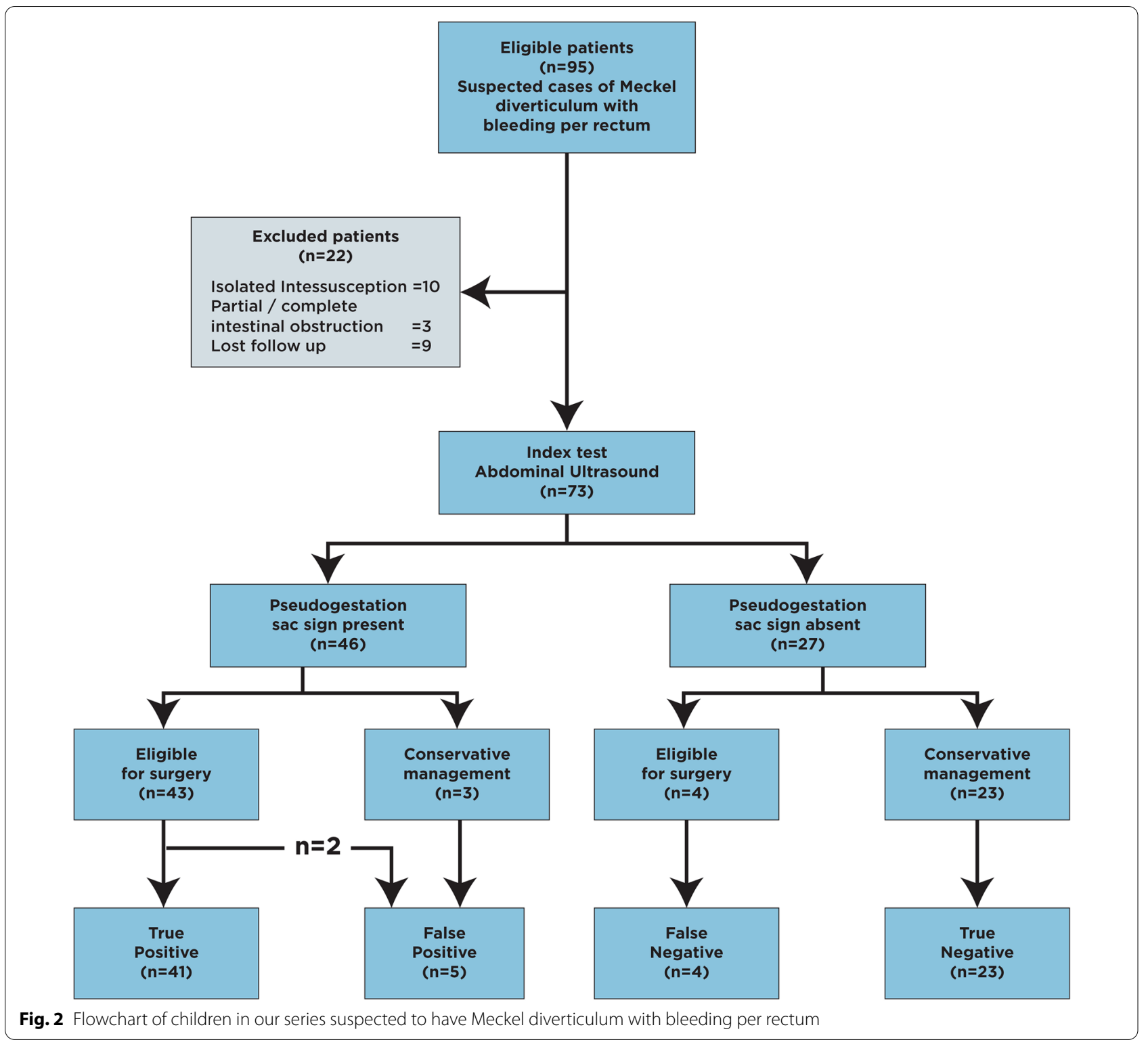

symptoms. Two cases proved to be Henoch-Schonlein purpura. The third patient proved to be ileal duplication cyst. The remaining two patients were operated and proved to be Meckel diverticulum by histopathology despite negative nuclear studies due to high clinical suspicion. The first patient was a 3-year-old male operated two days after negative nuclear study due to typical clinical features with massive bleeding per rectum. Histopathology showed ectopic gastric tissue within the diverticulum (Fig. 3). The second patient was a 9-year-old male who presented by intussusception and operated 6 years after initial ultrasound and negative nuclear study. Repeat ultrasound revealed a large intussusception associated with Meckel diverticulum. Histopathology showed gangrenous diverticulum with ectopic gastric and pancreatic heterotopia (Fig. 4).

\section{(See figure on next page.)}

Fig. 3 A 3-year-old boy with frank bleeding per rectum. a, b Ultrasound showed pseudogestational sac sign with peripheral vascularity on colour Doppler highly suggestive of Meckel's diverticulum. c Nuclear study done the following day was negative for Meckel's. $\mathbf{d}$ Intraoperative photograph showing the diverticulum. The boy was operated despite negative nuclear study due to typical clinical findings. Histopathology revealed Meckel's diverticulum lined by ileal-type mucosa and partly containing ectopic gastric tissue 

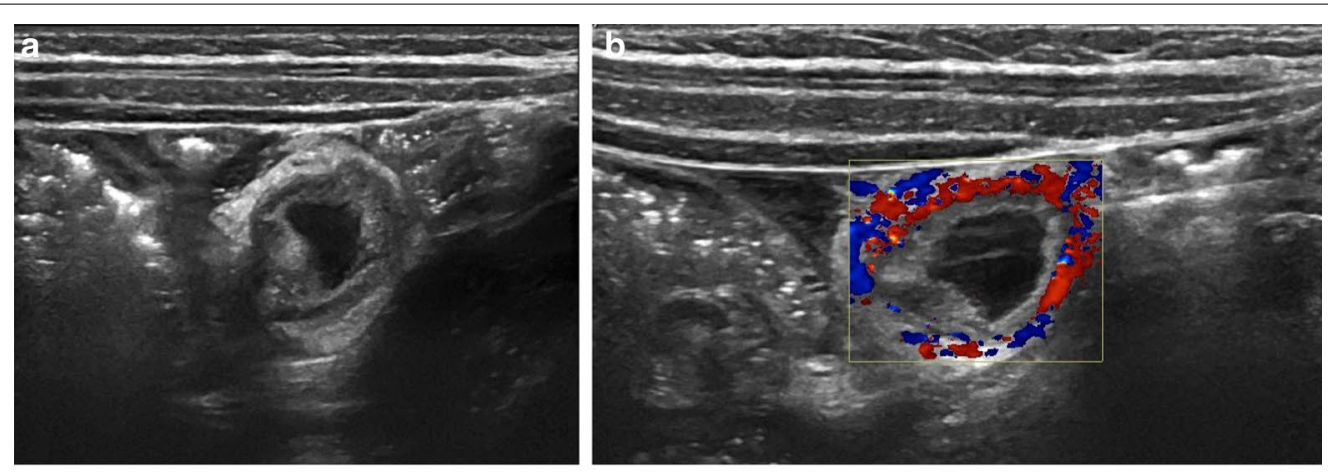

C
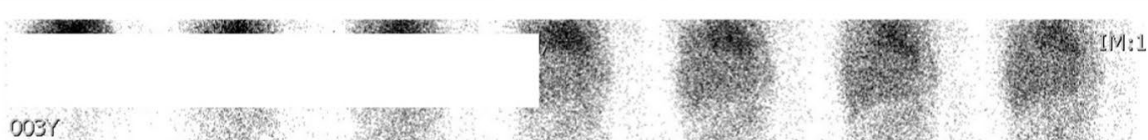

$003 Y$
$16 / 08 / 2000$
$003 Y$

Vascular Phase (8 sec/Frame)
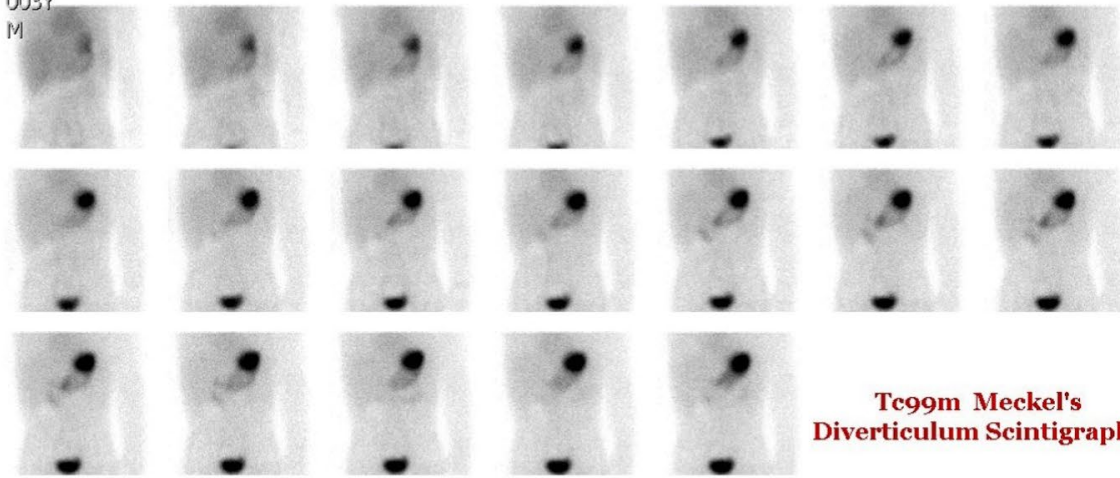

Excretory Phase (3 min/Frame)
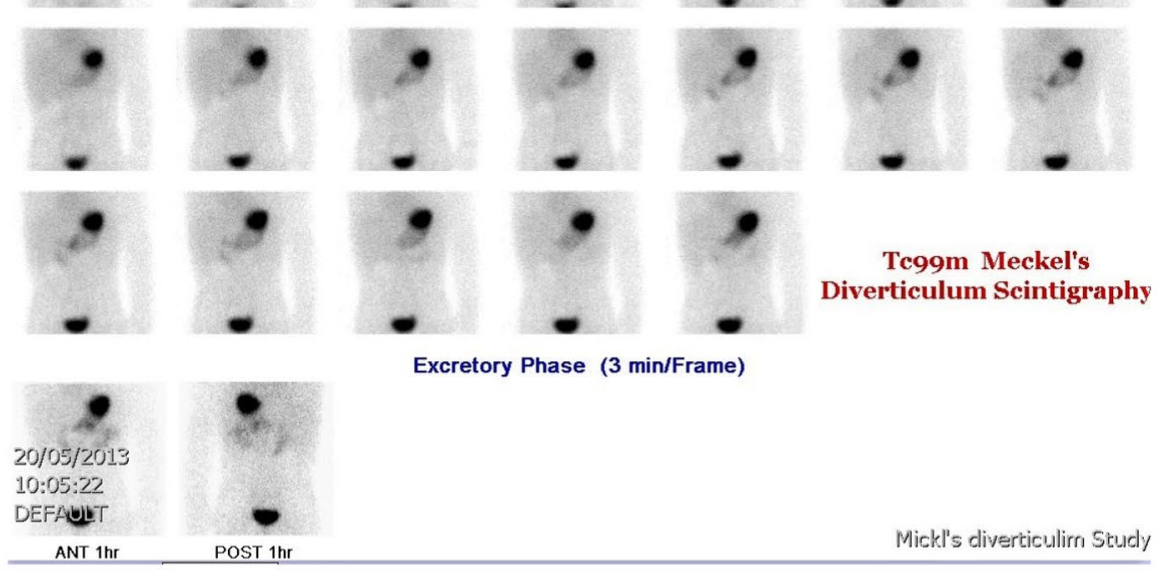

Teg9m Meckel's

Diverticulum Scintigraphy

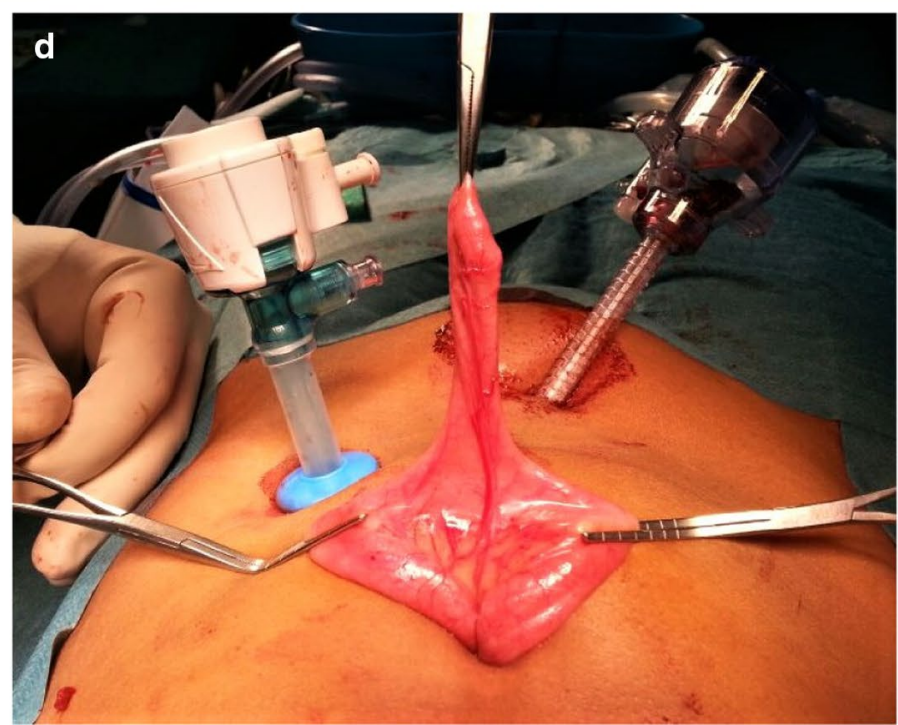

Fig. 3 (See legend on previous page.) 
The pseudogestational sac sign was absent in 27 patients (37\%). Four children were still operated despite negative ultrasound and confirmed to be Meckel diverticulum by laparoscopy and histopathology due to high clinical suspicion, persistent or recurrent bleeding per rectum and positive SPECT CT study. All four patients were wrongly diagnosed as acute appendicitis. The remaining 23 patients were treated conservatively. Seven patients underwent nuclear study before hospital discharge and proved all to be negative. After discharge, all 23 children were monitored clinically and by ultrasound with improvement in clinical symptoms, and no recurrence of bleeding per rectum for 6-month follow-up period and no other diseases diagnosed.

Forty-five patients were ultimately diagnosed with Meckel diverticulum by surgery and histopathology. Table 1 summarizes their clinical, imaging, operative and histopathology features. The age ranged from 2 months to 9 years with a mean of 2.3 years. The boyto-girl ratio was $4.6: 1$, with 26 (60\%) children presenting in their first 2 years of life. Ectopic gastric mucosa was the most commonly encountered heterotopia on histopathology seen in $36(80 \%)$ of patients. Table 2 summarizes the ultrasound features of the 41 true-positive cases. The largest lesion measured $4.0 \times 5.0 \mathrm{~cm}$, while the smallest lesion measured $0.8 \times 0.7 \mathrm{~cm}$ (Fig. 5). In addition to pseudogestational sac sign, ultrasound characteristics which were strongly associated with Meckel diverticulum in our series were wall thickness $\geq 3 \mathrm{~mm}$, hypervascularity on colour Doppler, surrounding inflammatory changes and enlarged mesenteric lymph nodes (Fig. 6).

Table 3 shows the results of ultrasound examination against the final diagnosis.

The ultrasound performance using the pseudogestational sac sign revealed a sensitivity of $91.1 \%$ (95\% confidence internal [CI] 78.8-97.5\%), specificity of $82.1 \%(95 \%$ CI $63.1-93.9 \%)$, positive predictive value of $89.1 \%$ (95\% CI 78.7-94.8\%), negative predictive value of $85.2 \%$ (95\% CI 67.0-93.7\%), positive likelihood ratio of 5.1 (95\% CI 2.3-11.4), negative likelihood ratio of 0.11 (95\% CI 0.040.28 ) and accuracy of $87.7 \%$ (95\% CI 77.9-94.2\%).

\section{Discussion}

Our results showed that a blind-ended cystic mass with thick echogenic wall clear or turbid content resembling early intrauterine or extrauterine gestational sac giving a pseudogestational sac appearance with surrounding inflammatory changes was highly suggestive of Meckel diverticulum in children presenting with bleeding per rectum [17]. Additional sonographic features supporting the diagnosis in our series were wall thickness $\geq 3 \mathrm{~mm}$, hypervascularity on colour Doppler and enlarged mesenteric lymph nodes as published by previous investigators $[1,2,6,13,14,18]$. As reported by $\mathrm{Hu}$ and colleagues, our results showed high sensitivity and accuracy in diagnosing Meckel diverticulum [2]. This was contrasted by one study which reported low sensitivity and accuracy of ultrasound which could be explained by their retrospective study design [12]. A study by Baldisserotto and colleagues also reported low sensitivity of ultrasound which could be due to a small number of children in their series with only ten children meeting their inclusion requirements. However, they concluded that ultrasound may be useful in children with bleeding per rectum and negative nuclear study [9].

The boys comprised $82.2 \%$ of Meckel diverticulum cases in our series similarly observed in other studies $[2,12,13]$. As reported by previous investigators, most of children in our series (60\%) presented during the first 2 years of life $[1,2,12,13,19]$. The smallest true-positive Meckel diverticulum in our series measured $0.8 \times 0.7 \mathrm{~cm}$ compared to $1.0 \times 0.4 \mathrm{~cm}$ in the study by $\mathrm{Hu}$ and colleagues [2]. Histopathological evaluation of Meckel's diverticulum cases in our series showed that gastric mucosa was the most commonly encountered heterotopia seen in $80 \%$ of patients similarly reported in previous studies $[1,12,16,19,20]$.

In out series, all our four false-negative cases were wrongly diagnosed as acute appendicitis (Fig. 7). Similar observation was reported by a study published by Baldisserotto and colleagues which included ten children with age ranging from 1 to 11 years who underwent preoperative ultrasound; six of those patients were misdiagnosed as having acute appendicitis [9]. Both acute appendicitis and Meckel diverticulum appear as blind-ended tubular structures which may explain the confusion. However,

\footnotetext{
(See figure on next page.)

Fig. 4 A 3-year-old boy presenting with bleeding per rectum. a 2D and $\mathbf{b}$ colour Doppler ultrasound examination revealed typical pseudogestational sac sign suggesting Meckel's diverticulum with hypervascularity on colour Doppler. c Nuclear study performed the following day was false negative for Meckel's. The boy presented 6 years later with recurrent bleeding per rectum. $\mathbf{d}$ Ultrasound examination revealed a large intussusception (solid white arrow) with a large Meckel's diverticulum (open white arrow) as the leading point. e Contrast enema was done with failed reduction after three attempts. f Intraoperative photograph showing a large gangrenous Meckel's diverticulum after intussusception reduction. Limited right hemicolectomy with ileo-ascending anastomosis was performed. Histopathology revealed gangrenous Meckel's diverticulum with intramural and extramural gastric and pancreatic heterotopia
} 

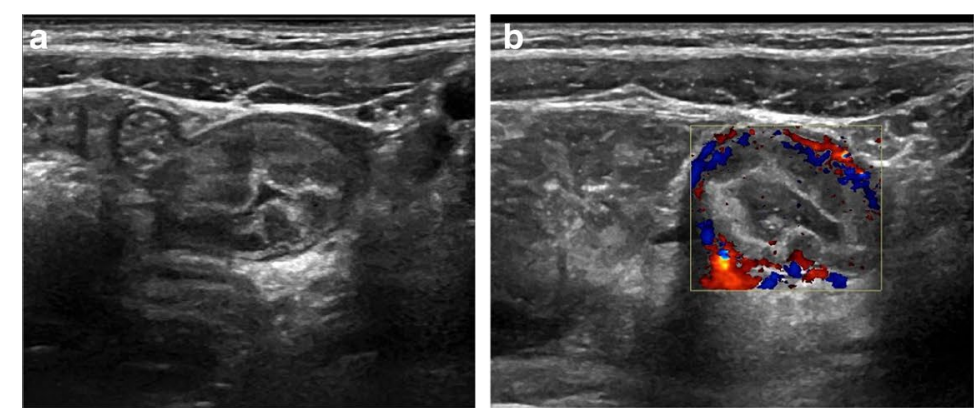

C
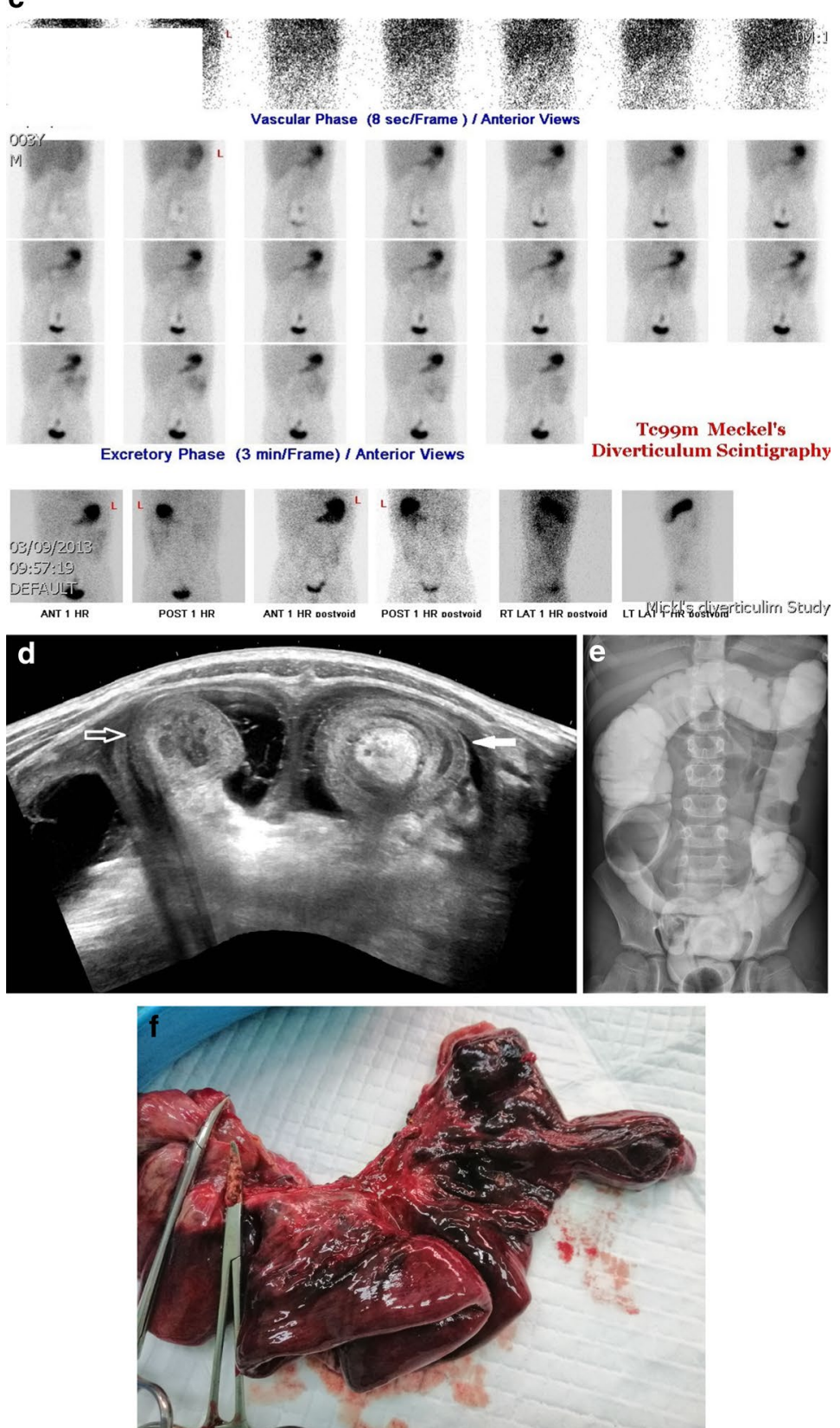

Fig. 4 (See legend on previous page.) 
Table 1 Clinical, imaging, operative and histopathological characteristics of 45 children with Meckel's diverticulum

\begin{tabular}{ll}
\hline $\begin{array}{l}\text { Patient characteristics signs and symptoms } \\
(\mathbf{n}=\mathbf{4 5})\end{array}$ & $\begin{array}{l}\text { Mean } \pm \text { SD } \\
\mathbf{n}(\%)\end{array}$ \\
\hline Age (years) & $2.3 \pm 2.0$ \\
$\leq 2$ & $27(60)$ \\
$>2$ & $18(40)$ \\
Sex & \\
Male & $37(82.2)$ \\
Female & $8(17.8)$ \\
Frank rectal bleeding & $23(51.1)$ \\
Bright red stool & $15(33.3)$ \\
Dark red or black stool & $7(15.6)$ \\
Abdominal pain & $31(68.9)$ \\
Vomiting & $5(11.1)$ \\
Ultrasound features ( $\mathrm{n}=45)$ & \\
Pseudogestational sac sign present & $41(91.1)$ \\
Pseudogestational sac sign absent & $4(8.9)$ \\
Nuclear study ( $\mathrm{n}=27$ ) & \\
Positive & $25(92.6)$ \\
Negative & $2(7.4)$ \\
Surgery ( $\mathrm{n}=45)$ & \\
Laparoscopic & $43(95.6)$ \\
Open & $2(4.4)$ \\
Histopathology ( $\mathrm{n}=45)$ & \\
Gastric heterotopia & $36(80)$ \\
Pancreatic heterotopia & $2(4.4)$ \\
Gastric and pancreatic heterotopia & $3(6.7)$ \\
Gastric and duodenal heterotopia & $1(2.2)$ \\
No heterotopia & $3(6.7)$ \\
\hline & \\
& \\
&
\end{tabular}

Table 2 Ultrasound features of true-positive cases

\begin{tabular}{ll}
\hline $\begin{array}{l}\text { Ultrasound features } \\
(\mathbf{n = 4 1 )}\end{array}$ & $\mathbf{n}(\%)$ \\
\hline Pseudogestational sac sign & $41(100)$ \\
Thickened wall $\geq 3 \mathrm{~mm}$ & $37(90.2)$ \\
Hypervascularity on colour Doppler & $40(97.6)$ \\
Surrounding Inflammatory changes & $35(85.4)$ \\
Mesenteric lymphadenopathy & $22(53.7)$ \\
Fluid collections & $7(17.1)$ \\
\hline
\end{tabular}

high index of suspicion has been given to these cases particularly with their clinical presentation of bleeding per rectum. A search for a normal appendix should also be carried out which can be identified in eight out of ten cases [21]. We misdiagnosed two cases as having Meckel diverticulum which later proved to be Henoch-Schonlein

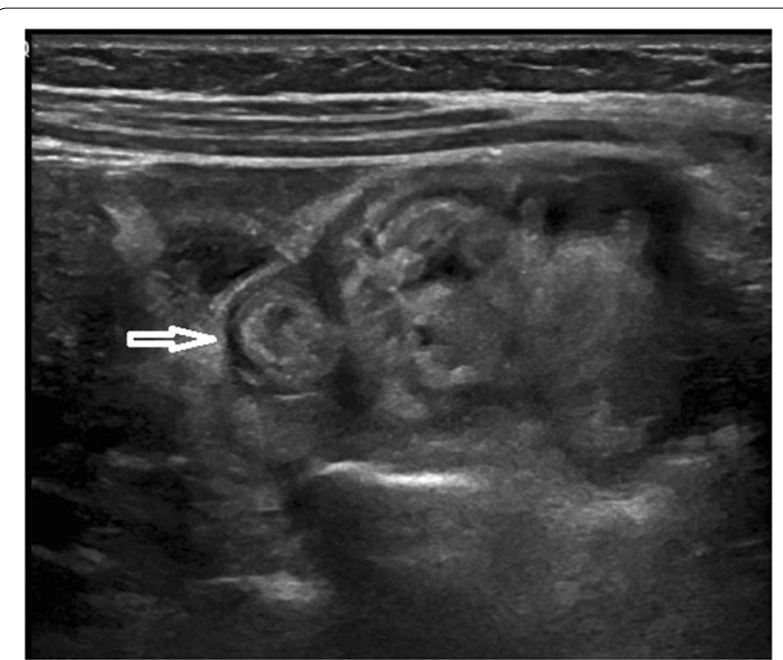

Fig. 5 A 6-month-old boy with frank bleeding per rectum. Ultrasound examination showed a small $0.8 \times 0.7 \mathrm{~cm}$ blind-ended lesion with a pseudogestational sac appearance associated with surrounding inflammatory changes (white arrow). Histopathology revealed perforated Meckel's diverticulum with ectopic gastric mucosa

purpura (Fig. 7). Ultrasound can differentiate Meckel diverticulum from allergic purpura by multiple segmental distribution and tendency to involve the proximal small bowel loops [2]. We had one false-positive case which turned out to be ileal duplication cyst (Fig. 7). The presence of ileal duplication cysts at the right iliac fossa may contribute to the confusion. Duplication cysts have no connection to the normal bowel, have a smooth outline and have a characteristic bowel wall signature which can help distinguish the condition from Meckel diverticulum $[2,13,22]$.

Thirty-seven children underwent nuclear study in our series with a $92.6 \%$ sensitivity and $94.6 \%$ accuracy which is higher compared to previous studies $[10,12$, 19, 23]. This could be explained by the fact that we only included children with bleeding per rectum in our series most of which had gastric heterotopia which improved the pickup rate. We also had seven patients who performed SPECT CT which has been shown to be more effective in diagnosing cases that would otherwise go undetected using conventional nuclear studies [20]. We had two cases with negative nuclear study who proved later to be Meckel diverticulum by surgery and histopathology. We also had true-positive cases in our series who did not perform nuclear study preoperatively. This illustrate that in the presence of typical clinical features, ultrasound can be considered an alternative sensitive technique in diagnosing Meckel diverticulum in paediatric population when nuclear imaging 


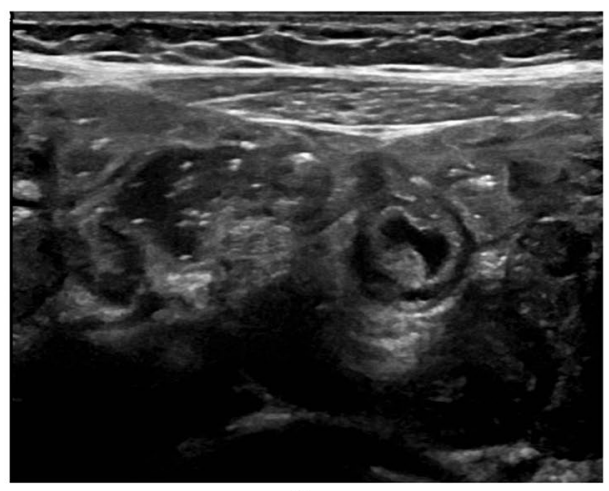

a

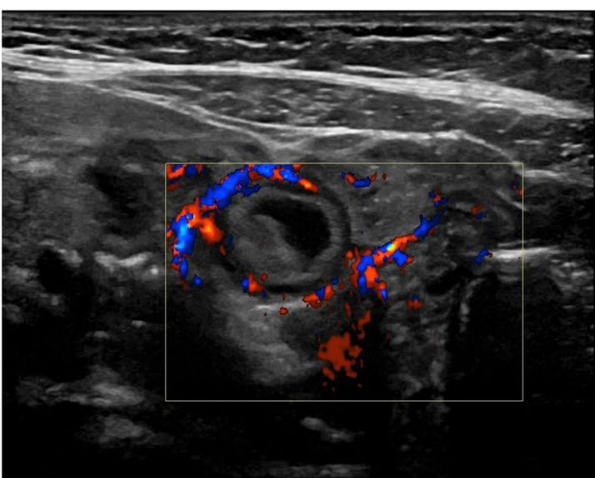

b

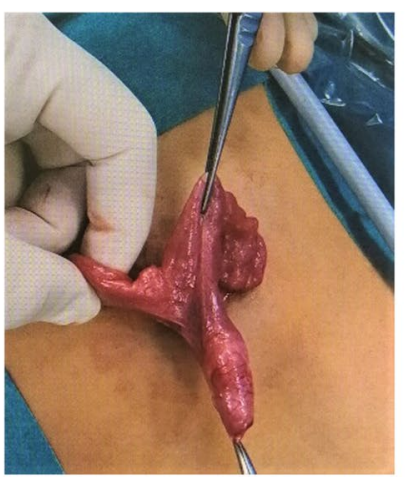

d

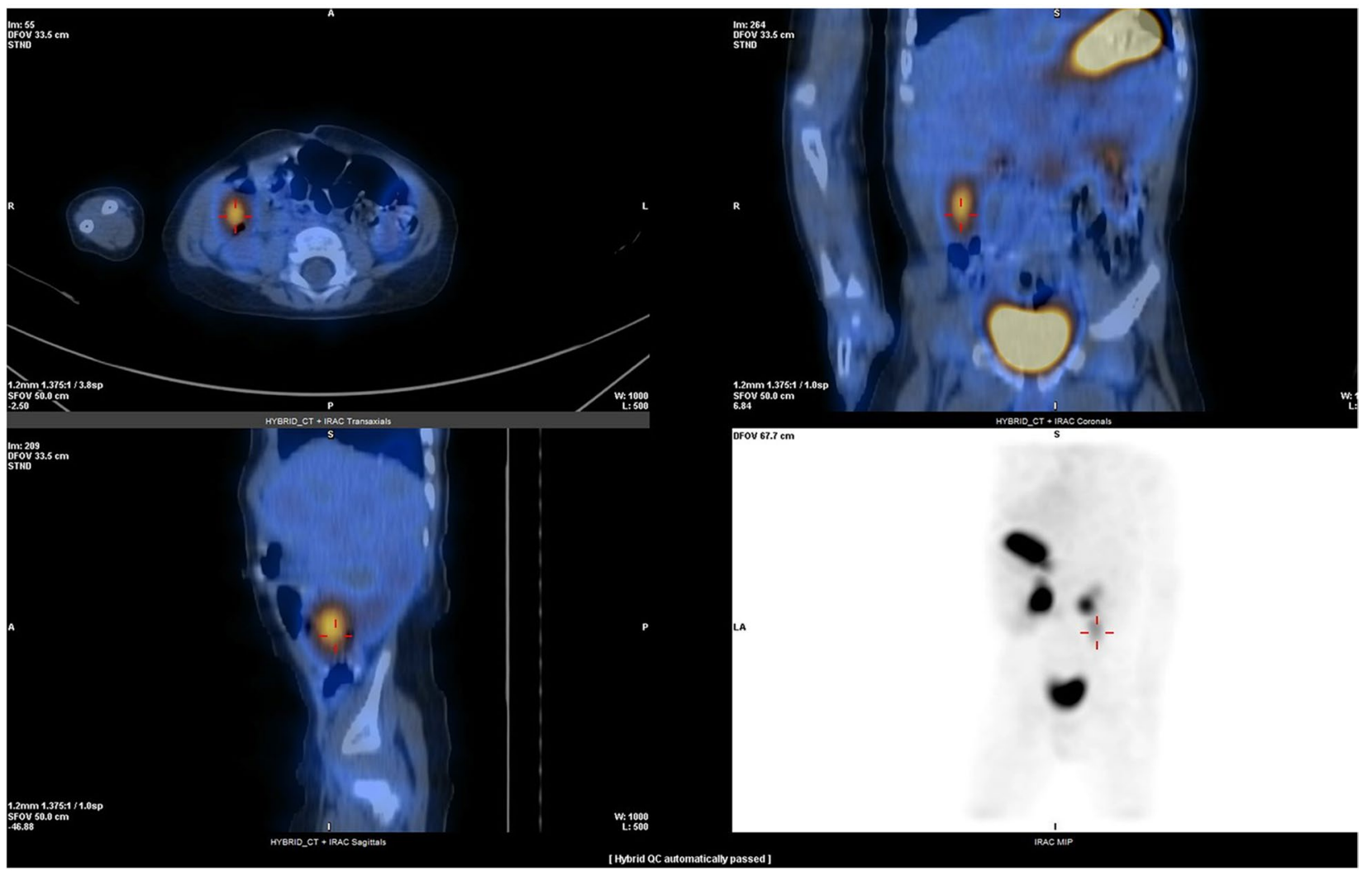

C

Fig. 6 A 10-month-old boy with frank bleeding per rectum. a, b Ultrasound showed pseudogestational sac sign with peripheral vascularity on colour Doppler highly suggestive of Meckel's diverticulum. c SPECT CT done 3 days later was positive for Meckel's showing a focal area of increased technetium uptake at the right lumbar region corresponding to the ultrasound abnormality. $\mathbf{d}$ Intraoperative photograph showing the diverticulum. Histopathology revealed Meckel's diverticulum showing heterotopic gastric mucosa with degenerative changes and chronic inflammation

\section{(See figure on next page.)}

Fig. 7 Examples of false-positive and false-negative diagnosis of Meckel diverticulum. a A 4-year-old boy with false-positive diagnosis of Meckel diverticulum which later proved to be Henoch-Schonlein purpura. Transverse ultrasound at the level of the gall bladder showed a lesion mimicking the pseudogestational sac sign. Nuclear study done after 4 days was negative. Clinical and follow-up assessment confirmed the diagnosis of Henoch-Schonlein purpura. b A 2-year-old girl with false-positive diagnosis of Meckel diverticulum and later diagnosed to be duplication cyst. Nuclear study done on the following day was negative. Retrospective analysis revealed a characteristic "gut signature" formed by the echogenic mucosa (open green arrow) and hypoechoic muscle layer (open red arrow). c, d A false-negative case of Meckel diverticulum diagnosed as acute appendicitis by ultrasound in a 6-year-old boy. Nuclear study performed on the following day showed a focus on increased updated at the right lower quadrant of the abdomen (read arrow). The findings were confirmed on surgery and histopathology 

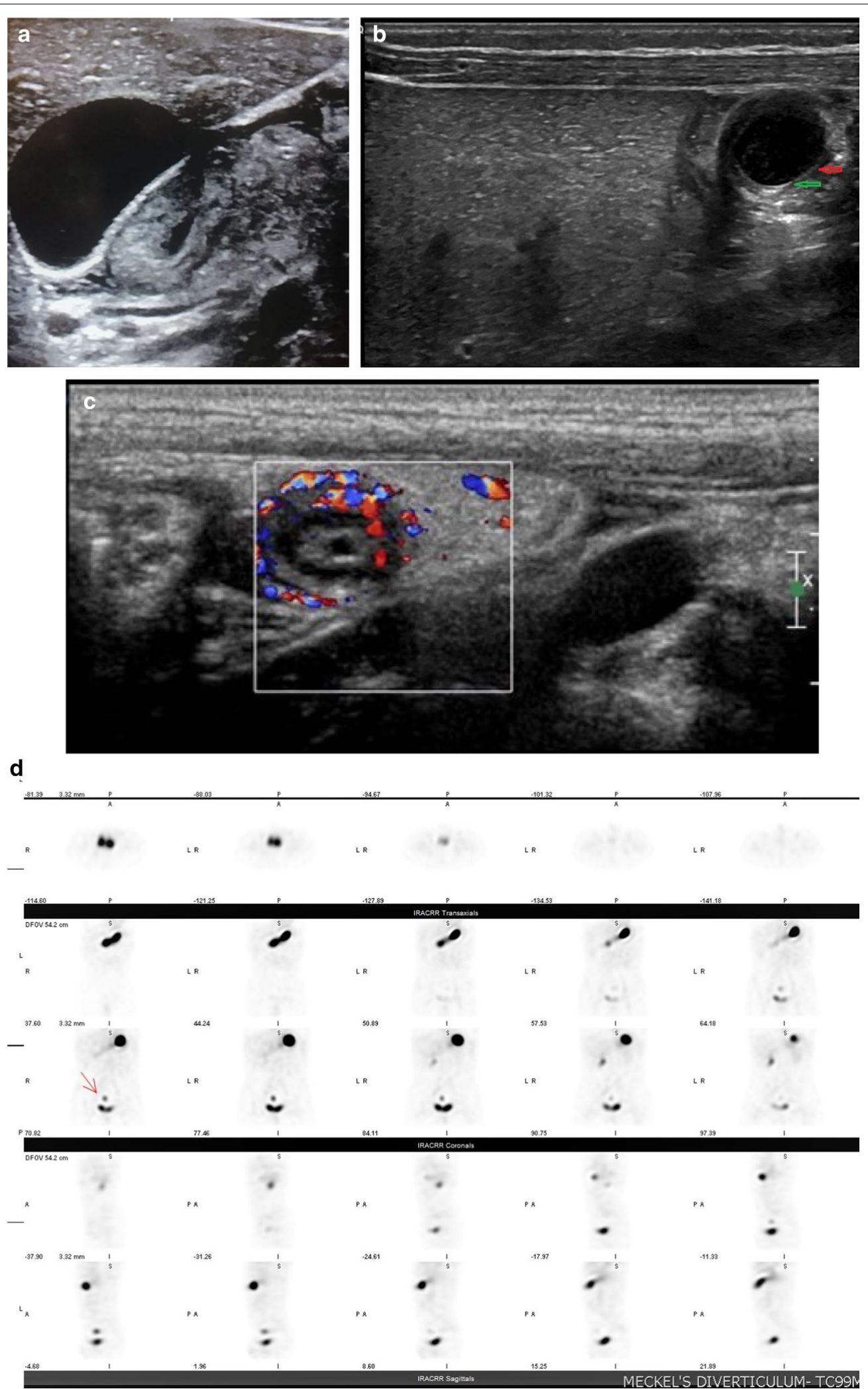

Fig. 7 (See legend on previous page.) 
Table 3 Ultrasound diagnosis versus final diagnosis for Meckel diverticulum

\begin{tabular}{llcc}
\hline Ultrasound diagnosis & \multicolumn{2}{l}{$\begin{array}{l}\text { Final diagnosis } \\
\text { follow-up) }\end{array}$} & Total \\
\cline { 2 - 3 } & $\begin{array}{l}\text { Meckel } \\
\text { diverticulum }\end{array}$ & Other & \\
\hline Meckel diverticulum & 41 & 5 & 46 \\
Other & 4 & 23 & 27 \\
Total & 45 & 28 & 73 \\
\hline
\end{tabular}

is not available, inconclusive or inconsistent with the clinical presentation.

The limitation of our study is the high incidence of Meckel diverticulum in our study population due to the way the patients were selected and the setting of the study at a tertiary paediatric and maternity hospital.

\section{Conclusion}

The sonographic pseudogestational sac sign is a reliable diagnostic tool for diagnosing Meckel diverticulum in children presenting with bleeding per rectum. The sonographic diagnosis of Meckel diverticulum complies with the international standards of "Image Gently" [24].

\section{Abbreviations \\ Cl: Confidence interval; STARD: Standards for Reporting Diagnostic Accuracy studies.}

\section{Acknowledgements}

Not applicable.

\section{Authors' contributions}

The scientific guarantor of this study is VNZ. SME was involved in review of the literature, data collection and analysis, performing ultrasound and reporting ultrasound findings, writing the original draft and reviewing and editing the manuscript. NA was involved in data collection and analysis and reviewing and editing the manuscript. VNZ was involved in suggesting the idea, data collection, performing ultrasound and reporting ultrasound findings and reviewing and editing the manuscript. All authors read and approved the final manuscript.

\section{Funding}

The authors declare that they did not receive funding for this research.

\section{Availability of data and materials}

The data sets used and analysed during the current study are available from the corresponding author on reasonable request.

\section{Declarations}

\section{Ethics approval and consent to participate}

Dubai Health Authority Research Ethics Committee approval was obtained. Reference number is not applicable. Written informed consent was obtained from the parents of all patients who agreed to take part in this study.

\section{Consent for publication}

All patients' guardians included in this research gave written informed consent to publish the data contained within the study.

\section{Competing interests}

The authors declare that they have no competing interests.

\section{Author details}

${ }^{1}$ Department of Radiology, National Cancer Institute, Cairo University, Cairo, Egypt. ${ }^{2}$ Department of Radiology, Medcare Women and Children Hospital, Sheikh Zayed Road, P.O Box 215565, Dubai, UAE. ${ }^{3}$ Department of Radiology, Latifa Hospital, Oud Metha Road, P.O. Box 9115, Dubai, UAE.

Received: 3 May 2021 Accepted: 28 July 2021

Published online: 05 August 2021

\section{References}

1. Srisajjakul S, Prapaisilp P, Bangchokdee S (2016) Many faces of Meckel's diverticulum and its complications. Jpn J Radiol 34:313-320

2. Hu Y, Wang X, Jia L, Wang Y, Xin Y (2020) Diagnostic accuracy of highfrequency ultrasound in bleeding Meckel diverticulum in children. Pediatr Radiol 50:833-839

3. Robinson JR, Correa H, Brinkman AS, Lovvorn HN 3rd (2017) Optimizing surgical resection of the bleeding Meckel diverticulum in children. J Pediatr Surg 52:1610-1615

4. Blevrakis E, Partalis N, Seremeti C, Sakellaris G (2011) Meckel's diverticulum in paediatric practice on Crete (Greece): a 10-year review. Afr J Paediatr Surg 8:279-282

5. Swaniker F, Soldes O, Hirschl RB (1999) The utility of technetium 99m pertechnetate scintigraphy in the evaluation of patients with Meckel's diverticulum. J Pediatr Surg 34:760-765

6. Elsayes KM, Menias CO, Harvin HJ, Francis IR (2007) Imaging manifestations of Meckel's diverticulum. AJR Am J Roentgenol 189:81-88

7. Lüdtke FE, Mende V, Köhler H, Lepsien G (1989) Incidence and frequency or complications and management of Meckel's diverticulum. Surg Gynecol Obstet 169:537-542

8. Kotecha M, Bellah R, Pena AH, Jaimes C, Mattei P (2012) Multimodality imaging manifestations of the Meckel diverticulum in children. Pediatr Radiol 42:95-103

9. Baldisserotto M, Maffazzoni DR, Dora MD (2003) Sonographic findings of Meckel's diverticulitis in children. AJR Am J Roentgenol 180:425-428

10. Irvine I, Doherty A, Hayes R (2017) Bleeding Meckel's diverticulum: a study of the accuracy of pertechnetate scintigraphy as a diagnostic tool. Eur J Radiol 96:27-30

11. Rushford MP, Stys SJ, Latchaw LA, Kasales C, Vaccaro T (2004) Prenatal sonographic detection of Meckel diverticulum in utero with postnatal radiologic and surgical confirmation. J Ultrasound Med 23:319-321

12. Lin XK, Huang XZ, Bao XZ, Zheng N, Xia QZ, Chen CD (2017) Clinical characteristics of Meckel diverticulum in children: a retrospective review of 15-year single-center experience. Medicine (Baltimore) 96:e7760. https:// doi.org/10.1097/MD.00000000000007760

13. Daneman A, Lobo E, Alton DJ, Shuckett B (1998) The value of sonography, $\mathrm{CT}$ and air enema for detection of complicated Meckel diverticulum in children with nonspecific clinical presentation. Pediatric Radiol 28:928-932

14. Baldisserotto M (2004) Color Doppler sonographic findings of inflamed and perforated Meckel diverticulum. J Ultrasound Med 23:843-848

15. Mostbeck GH, Liskutin J, Dorffner R, Bittmann B, Resinger M (2000) Ultrasonographic diagnosis of a bleeding Meckel's diverticulum. Pediatr Radiol 30:382

16. Menezes M, Tareen F, Saeed A, Khan N, Puri P (2008) Symptomatic Meckel's diverticulum in children: a 16-year review. Pediatr Surg Int 24:575-577

17. Zevof VN, El-Maadawy SM, Abdelrahman NA, Abdul Rahman D, Mustafawi AR (2017) Value of sonographic pseudogestation sac sign in diagnosing Meckel diverticulum in children presenting with bleeding per rectum: a decade's experience. ECR 2017 Book of Abstracts. Insights Imaging 8:S293. https://doi.org/10.1007/s13244-017-0546-5

18. Chang PT, Schooler GR, Lee EY (2015) Diagnostic errors of right lower quadrant pain in children: beyond appendicitis. Abdom Imaging 40:2071-2090

19. Burjonrappa S, Khaing P (2014) Meckel's diverticulum and ectopic epithelium: evaluation of a complex relationship. J Indian Assoc Pediatr Surg 19:85-89. https://doi.org/10.4103/0971-9261.129601

20. Levy AD, Hobbs CM (2004) From the archives of the AFIP. Meckel diverticulum: radiologic features with pathologic correlation. Radiographics 24:565-587 
21. Rioux M (1992) Sonographic detection of the normal and abnormal appendix. AJR Am J Roentgenol 158:773-778

22. Hwang IK, Namkung S, Kim BS, Kim HC, Lee IS, Hwang WC (2003) Perforated ileal duplication cyst with haemorrhagic pseudocyst formation. Pediatr Radiol 33:489-491

23. Thurley PD, Halliday KE, Somers JM, Al-Daraji WI, llyas M, Broderick NJ (2009) Radiological features of Meckel's diverticulum and its complications. Clin Radiol 64:109-118
24. Applegate KE, Frush DP (2017) Image gently: a decade of international collaborations to promote appropriate imaging for children. J Am Coll Radiol 14:956-957

\section{Publisher's Note}

Springer Nature remains neutral with regard to jurisdictional claims in published maps and institutional affiliations. 